\title{
USOS I ABUSOS DE LES ENQUESTES EN ELS ESTUDIS SOBRE LA JOVENTUT *
}

\author{
Salvador Cardús i Ros \\ (Universitat Autònoma de Barcelona)
}

\section{LUSS I ABUSS COMENÇA EN LA MATEIXA DEFINICIO DE L'OBJECTE D'ANALISI QUE HOM VOL ESTUDIAR}

Sembla raonable de postular que l'elecció d'una problemàtica d'estudi des de la sociologia s'ha de fer segons els criteris $i$ dins els límits que aquesta mateixa disciplina defineix.

És a dir, que sigui quin sigui l'objecte d'anàlisi que hom ha de definir, aquest sorgeix amb posterioritat a la discussió d'una problemàtica sociolò gicament definida.

Si la sociologia ha d'afegir quelcom d'original i nou al discurs sobre el que és social, i no s'ha de limitar a ser una simple teproducció més o menys fidel de la ideologia i els estereotips que són de domini comú - dits en llenguatge «savi»-, cal que sigui la mateixa disciplina, $i$ des de les seves elaboracions conceptuals més sólides, la que imposi els límits i l'abast que li han de ser propis.

* És del tot necessari advertir que les reflexions que contenen aquestes ratlles no són fruit d'una «especialització» en el tema de la joventut, sinó senzillament del recull d'alguns dels elements que ens han semblat més interessants d'un informe teIativament extens que realitzàtem l'any 1983 per a la Direcció General de Joventut de la Generalitat de Catalunya. L'informe és fet, doncs, des d'una preocupació fonamental envers la utilització de la sociologia con a disciplina científica, en aquest cas, en els estudis sobre la joventut. Vegeu Salvador Sardús i Joan Estruch, Les enquestes a la joventut de Catalunya. «Bells deliris fascinen la taó», Barcelona, Direcció General de Joventut, 1984. 
Aquest principi que sembla elemental, i que és ben respectat en moltes disciplines científiques, pel que fa a la sociologia i altres ciències socials no sempre és tingut prou en compte. I aquest és també, $i$ fonamentalment, el primer entrebanc amb el qual ensopeguen els estudis sobre la joventut. Oi més quan, en el cas de la joventut, en els darrers anys ja no sols és "tema» d'investigació sinó que sembla voler-hi figurar com a «especialitat» -resulta que hi ha sociòlegs $\mathrm{i}$ sociologia de la joventut, i revistes especialitzades, i números monogràfics que en parlen...

En aquests casos, els principis fonamentals, diguem-ne epistemològics, que suara exposàvem, hom se'ls ha saltat «a là torera» 0 , si voleu, "olímpicament».

Cal fer notar que ben aviat els mateixos usuaris d'aquest «objecte» d'estudi que és la joventut s'han adonat de les limitacions inevitables -i insalvables- de la seva utilització. Gairebé ningú no comença avui dia un estudi sobte la joventut sense excusar-se pel terme, fer-ne notar el problema de la delimitació cronològica, insistir en la diversitat àmplia que engloba o avisar dels perills d'ús ideològic. Petò, poques ratlles tués avall, hom acaba definint edats inicials i finals del grup, generalitzant sobre la joventut $i$, en definitiva, construint elaboracions més ideològiques que analítiques, encara que amb la bona imatge que els pugui proporcionat un bon vernís de cientifititat.

És ben cert que aquest tipus de crítica la podríem fer extensiva a moltes altres «especialitzacions» del discurs sociològic. Tanmateix, el de la joventut $n$ 'accentua molt els vicis i esdevé així paradigmàtic. Sobretot, cal tenir present que, quan hom parla de «joventut», gairebé mai els estudis no es refereixen a la categoria històrica que indica el terme, sinó sobretot i en concret al "coniunt d'individus joves», sitració encara més indefen. sable. Fet $\mathrm{i}$ fet, és com si hom volgués reduir la sociologia del treball a la sociologia dels qui treballen, per posar un exemple.

Naturalment, darrera d'aquestes tendències que critiquem no hi ba únicament una «badada epistemològica», o una incapacitat professional. Atribuir-ho exclusivament, $i$ en tots els casos, a això, a més de fals i groIler, seria pedant.

Més aviat cal pensar en dos contratemps que ho poden acabar d'explicar. Hi ha, d'una banda, una certa concepció del que ha de ser la pràctica sociològica que és relativament diferent de la nostra. D'altra banda, petò anant a parar al mateix lloc, hauríem de parlar també d'una certa concepció relativament distinta de la nostra respecte a la utilitat del sociòleg.

Més concretament volem dir que, sovint, el tipus de sociologia que semblen proposar implícitament els estudis sobre la joventut és aquella que implica alguna mena d'intervenció social, i que, bo i renunciant a la «com- 
prensió des de fora», prefereix una «explicació útil des de dins». Llavors hom pot sentir disbarats - sociològicament parlant-r com els de si pet fer estudis sobre la joventut cal ser jove, o bé, com deien ja fa més de cinquanta anys els sociòlegs de l'anomenada escola de Chicago, que no és possible fer estudis des d'un despatx, sinó que cal «embrutar-s'hi les mans».

Però també és cert, $i$ aquest és el segon contratemps, que els qui encarreguen estudis de sociologia busquen sovint en el sociòleg aquell aliat que els permetrà atorgar tuna categoria científca o si més no uns fonaments aparentment científics a llur presa de decisions.

Aquesta coincidència té diferents nivells de lectura i justificació. Per exemple, des de la defensa de la necessitat de "compromís social» del científic, passant per l'acusació de tancament en una utorre d'ivori» a aquell qui no s'hi subjecta, fns a aquell nivell d'explicació menys elegant i més clar del «qui paga mana».

En qualsevol cas, aquesta coincidència entre una sociologia que es vol «intervencionista» $i$ un patró que necessita legitimacions pseudocientífques pet a la seva acció fa que, de mica en mica, la divisió de la sociologia en especialitats s'acosti més i més a la divisió de l'administració en regidories, departaments $\mathrm{i}$ direccions generals.

\section{VISTOS L'OBJECTE PREDEFINIT I LES NECESSITATS DE QUI TRUCA A CAL SOCIOLEG, NOMES QUEDA UNA POSSIBILITAT: ENQUESTAR I RECOMPTAR}

Així, doncs, si l'objecte d'estudi és definit per una àrea concreta de l'administració $i$, en definitiva, per a individus que són susceptibles de ser controlats $o$ dirigits amb més o menys eficàcia $i$ en un o altre sentit, $i$, a més, si qui va a buscar un sociòleg, en general $i$ amb excepcions tan escasses com notables, necessita o bé un bon «estudi de mercat» per a la previsió de conductes o bé una base «científica» per a legitimar les decisions preses prèviament, el sociòleg no té altre remei que «passar una enquesta» $i$ fer recomptes més o menys fins $i$ sofisticats.

En general, doncs, la proliferació d'estudis i estudis que darrerament ha sorgit al nostre país està sota els efectes d'aquests determinants: gairebé tots consisteixen en els informes més o menys interessants d'enquestes de tota mena, fetes no sempre amb el mínim de rigor exigible.

Ens trobem, doncs, fonamentalment amb estudis quantitativistes, on la dada i el percentatge són els "senyors», sense explicitacions prèvies ni de bases teòriques ni tan sols d'hipòtesis de treball, $i$ on la crítica metodo- 
lògica és, per tant, prèvia o, si es vol, suficient per a desemmascarar el seu escàs valor.

Per tant, hem de qualificar els estudis de «sociologia de la joventut» com a exponents privilegiats de les dues característiques que, de fet, són prou generals a la sociologia que es practica a casa nostra: l'esquifidesa de les elaboracions teòriques i el quantitativisme ingenu.

1 , a més, tot això sovint posat al servei de la validació «científica» dels estereotips dominants, oferint la sociologia, amb la seva complicitat amb el polític, la manera de certificar-li la «certesa» de les seves posicions.

En les ratlles que seguiran, ens limitarem al comentari d'alguns dels trets específics d'aquest quantitativisme ingenu que domina el panorana dels estudis sobre la joventut, no perquè sigui el més greu, sinó perquè, si més no, és el que resta de tot allò que suara comentàvem. Mal podríem entrar en la crítica teòtica allí on no hi ha teoria, $i$ encara menys passar a l'anàlisi o al judici d'intencions respecte a complicitats que mai no s'expliciten.

\section{EL QUANTITATIVISME INGENU: \\ MES QUE NO PAS DAVANT DUUNA METODOLOGIA, ESTEM DAVANT DUN POTI-POTI}

No es tracta pas ara d'insistir en els efectes màgics que per elles mateixes tenen les xifres, ni en les connotacions «científiques» que adquireix ipso facto tota afirmació que recolza en un elemental percentatge. Que els efectes màgics fossin effcaços en els neòfits en l'art de mentir estadísticament, això seria prou d'esperar $i$ fins tolerable. El mal és, però, que fins en els professionals de l'estadística - - com sembla que definitivament ens volen o ens volem deixar qualificar els sociòlegs - aquesta màgia tingui els seus efectes. I si en certs camps l'autoengany pot ser més comprensible que l'engany a l'altre, entre sociòlegs la seducció de les xifres i per les xifres hauria de ser imperdonable.

Sembla, doncs, com si la seducció de la xifra immobilitzés els antígens crítics del cos del sociòleg envers els quüestionaris i aquests s'imposessin abusivament.

Vegem on rauen, fonamentalment, les causes d'aquest abús de l'enquesta.

En primer lloc hi ha el fet, que per elemental no és menys greu, de saber quina mena de "realitats» vol posar en relleu o copsar el qüestionari a través de les múltiples preguntes possibles. No és el mateix de- 
manar l'edat exacta de l'enquestat que demanar-li si celebra els aniversaris, ni preguntar.li què opina dels qui s'amaguen anys. Des de la resposta objectiva, passant per la relativa a les conductes, fins a arribar a les opinions, ens trobetn davant preguntes de molt diversa rellevància i de fiabilitat no menys diversa, $\mathbf{i}$ en definitiva ens referim a «realitats» socials amb carac. terístiques específiques $i$ no reduibles a un tractament únic. En getneral, els qüestionaris obliden aquest fet fonamental: d'entrada no distingint les diferents categories de preguntes, $i$ de sortida fent d'unes $i$ altres un tractament numètic únic $i$ absolutament reduccionista. ${ }^{1}$

Però si aquesta és una qüestió que hauria de semblar clara $i$ evident, en canvi passa més desapercebuda - $-\mathrm{i}$ per tant és més greu- la segona causa d'abusos. Ens referim al fet que tot qüestionari significa la imposició d'una problemàtica especifica a l'enquestat. A l'hora de decidir el contingut de les preguntes d'un qüestionati és inevitable haver de decidir quines temàtiques hom creu pertinents d'abordar. Tanmateix, aquesta elecció no és l'única possible.

Ens trobem, doncs, en el cas que, d'una banda, és ineludible que l'elecció de la temàtica que cal tractar es faci també des de criteris sociològics, això és, definits prèviament i teòrica segons unes tesis $i$ unes hipòtesis que se suposa que l'investigador ha explicitat. Tanmateix, si habitualment eis estudis sobre la joventut no disposen d'aquest aparell conceptual i teòric, con podem trobar la justificació sociològica -i no política o ideològicade la imposició d'aquella determinada problemàtica en el qüestionari?

D'altra banda, a més, i malgrat una possible i poc probable justificació sociològica de la problemàtica definida, no hi ha cap garantia que aquesta problemàtica sigui pertinent per al destinatari del qüestionari. Dit altrament, que àdhuc aquelles problemàtiques «sociològicament raonables» de demanat en un qüestionati no és gens segur que siguin, per a l'entrevistat, ni pertinents, ni comprensibles, ni conegudes.

Tot plegat recolza en un error gravíssim, i que consisteix a suposar que «tothom té opinió de tot» i que les diverses opinions són comparables, homogènies i igualment valuoses. I aquest error, ben segur, té el seu fonament en una mena d'infiltració del «parlamentarisme democràtic» a les enquestes d'opinió, que faria que per a aquestes últimes també valgués la màxima «un home, un vot», traduida en «un home, una opinió».

Per tant, i recollint els errots fonamentals de les enquestes, especialment les «d'opinió», tal com els definíem a l'estudi citat (pp. 105-6), ens caldria concloure que:

1. Per a una exempliffcació precisa, vegeu el nostre estudi Les enquestes a la joventut de Catalunya, ja citat. 
a) Les enquestes d'opinió es basen en l'error de suposar que hi ha consens sobre les preguntes que cal plantejar.

b) Les enquestes d'opinió es basen en l'error de suposar que totes les respostes volen dir el mateix.

c) Les enquestes d'opinió es basen en l'error de suposar que totes les opinions són equivalents.

d) Les enquestes d'opinió es basen en l'error de pressuposar la coherència de les opinions individuals.

e) Les enquestes d'opinió es basen en l'error de suposar que tothom té una opinió.

Vist això, no ens hauria de ser massa difícil d'acceptar que, sovint, els «no contesta», que són sistemàticament oblidats o abusivament manipulats en els estudis que suara comentem, molt bé podrien representar l'única alternativa valida $i$ bonesta de resposta a preguntes que es mouen entre la impertinència, la no pertinència $i$ el confusionisme més descarat. I en això, el tracte que reben els «no contesta» dels qüestionaris no és menys intolerant, per part dels «sociòlegs-porta-platets», que el que reben els abstencionistes per part dels polítics en les conteses electorals.

Finalment, respecte a aquests usos i abusos de les enquestes d'opinió, i deixant de banda qüestions més tècniques, ens caldria referir-nos a les interpretacions de resultats a què són sotmeses.

I, en aquest aspecte, hi ha diversitat de gustos, que van des de l'absència total d'interpretació, passant pel comentari «en prosa» dels quadres estadístics que eten «en vers», fins a la interpretació abusiva, més enllà de les ja poc fiables dades obtingudes a través del qüestionari.

És així com retrobem aquell vici ja criticat fa temps per Sorokin quan parlava d'una «paintul elaboration of the obvious» i aquell altre vici de deixar que els propis prejudicis emmascarin qualsevol resultat. Ni que siguin els únics exemples concrets d'aquestes pàgines, deixeu-nos-en exposar dos. En un cas, tenim aquella «interpretació» relativa a la parla del català en un estudi avalat per una empresa de prestigi, que deia: «un jove té més probabilitat de parlar habitualrnent en català si els seus pares també el parlen habitualment». ¿Potser això, si no fos per la informàtica, mai no s'hauria pogut saber...? En l'altre cas, un estudi en el qual, del fet que un sol individu hagi respost que, pel que fa al lleure, li agrada «estar sol», l'autor es veu capaç d'afirmar: «No resulta representatiu, però és important veure que hi ha un cert corrent que podríem estimat de l'u per mil de joves que tenen per afecció l'estar sols. Pensem que aquesta actitud, si bé és de molt poca magnitud, és una denúncia de com tenim organitzada la societat.» D'això també se'n pot dir «voler fer entrar el clau per la cabota». 


\section{CONCLUSIONS. UNA TRIPLE NECESSITAT \\ I UN OBJECTIU UNIC: DADES ESTADISTIQUES FIABLES, MARCS DE REFERENCIA TEORICS I MONOGRAFIES TEMATIQUES, PERO SEMPRE A LA RECERCA D'UN TREBALL INDEPENDENT}

Malgrat la brevetat de les notes fins ara apuntades, hom s'adona que la major part dels estudis sobre la joventut tenen molt poca cosa d'esforç de comprensió metòdica i científica de la realitat i molt d'amplificació de pressupòsits ideològics dels autors, de traducció dels interessos de qui els ha encarregat $\dot{i}$, en tot cas, de pura reproducció dels estereotips dominants. La seva crítica ideològica és, doncs, la crítica o bé dels criteris implícits dels mateixos sociòlegs o bé de la ideologia dominant i conformadora «d'estats d'opinió pública» prèviament imposats pels miti̧ans de comunicació.

La manera de sortir d'aquest — des del nostre punt de vista- «còmode atzucac» en què es troba sovint la sociologia rau en una triple recepta.

D'una banda calen dades estadistiques objectives i fables. Aquestes no haurien de ser resultat d'estudis d'opinió o conducta, sinó fruit dels serveis de l'Administració. Sense haver de convertir el sociòleg en funcionari recomptador, en canvi aquell es podria beneficiar del coneixement que l'Administració podria tenir - $\mathrm{i}$ hauria de tenit?- dels administrats.

D'altra banda, hem repetit insistentment que és ineludible partir d'uns marcs conceptuals definits sociològicament per procedit a qualsevol tipus d'investigació. I si no es vol que cada investigador hagi de començar de zeto en la construcció d'aquests marcs teòrics, sempre hi ha la possibilitat del treball en equips, de les planificacions a mig termini de diverses investigacions, de l'intercanvi entre científics, etc., etc. El treball alllat i individualitzat i la manca de crítica afavoreixen el manteniment d'uns procedi. ments que cada vegada haurien de ser més residuals en la investigació sociològica actual.

I és en aquest sentit, també, que les monografies temàtiques suposarien l'aprofundiment en aspectes específics i segons uns plans més o menys ambiciosos $i$ coherents, $i$ evitarien que cada estudi torni a repetir exactament tots els passos previs i caigui per tant en tots els mateixos etrors de les investigacions anteriors.

Finalment, $i$ per acabar, diguem que, tot $i$ que no és aquest el lloc ni ara el moment per a debatre-ho, estexn persuadits que només una investigació sociològica independent esdevé a la llarga útil per a la mateixa societat que l'ha feta possible, mentre que, fins $i$ tot a la curta, una investigació a mercè dels interessos de qui l'encarrega esdevé la més inútil de les investigacions possibles. 